\title{
Decreased Distensibility of a Passive Vascular Bed in Diabetes Mellitus: An Indicator of Microangiopathy?
}

\author{
I. Faris, K.Agerskov, O. Henrikson, N. A. Lassen and H.-H. Parving \\ Department of Clinical Physiology, Bispebjerg Hospital, Steno Memorial Hospital, Gentofte, and Department of Medicine F, Herlev Hospital, \\ University of Copenhagen, Denmark
}

\begin{abstract}
Summary. This study was undertaken to determine whether the distensibility of a passive vascular bed is reduced in Type 1 (insulin-dependent) diabetic patients with microangiopathy. The change in blood flow induced by $45^{\circ}$ head-up tilting was studied in two systems: (a) following maximal ischaemic exercise and (b) in a vascular bed locally paralysed by the injection of papaverine. Five normal subjects, six patients with long-standing Type 1 diabetes and six non-diabetic patients with severe atherosclerosis affecting the legs were studied. Blood flow was measured in the anterior tibial muscle by the isotope washout technique. The median increase in blood flow produced by tilting was greater in normal subjects than in diabetic subjects in both the locally-relaxed bed $(58 \%$
\end{abstract}

and $14 \%$ respectively) and after maximal ischaemic exercise ( $45 \%$ and $4 \%$ respectivley). In the atherosclerotic subjects, the increase in blood flow in the locally relaxed bed was $77 \%$. The results are consistent with the hypothesis that the reduced distensibility seen in the diabetic subjects was related to the presence of microvascular disease and that the behaviour of a vascular bed relaxed by the local injection of papaverine might be an appropriate model to study this condition.

Key words: Type 1 diabetes, diabetic microangiopathy, skeletal muscle, blood flow measurement, ${ }^{133} \mathrm{Xe}$ washout, maximal ischaemic exercise, papaverine, atherosclerosis.
The maximum blood flow which can be obtained in a vascular bed, for a given perfusion pressure $\left(\mathrm{P}_{\mathrm{a}}-\mathrm{P}_{\mathrm{v}}\right)$, depends on the resistance in the inflow system (large artery resistance) and the minimal resistance obtainable in the microvascular bed (microvascular resistance). A raised microvascular resistance has been used as an indicator of structural change in patients with arterial hypertension $[1,2]$, but comparable studies have rarely been carried out in diabetic subjects. Neubauer [3] reported that the combination of regional vasodilatation produced by ischaemic exercise and an increase in transmural pressure produced by head-up tilt might give an early indication of developing large artery obstruction. He observed that the increase in post-ischaemic exercise blood flow in the anterior tibial muscle upon change in body posture was less in diabetic than in normal subjects and concluded that the difference was due to subclinical obstruction of larger arteries. However, this explanation seems unlikely, because it would be necessary to postulate that, after ischaemic exercise performed when supine, the blood flow was limited by the capacity of the large arteries so that further increase was restricted. However, measurement of the resistance in large arteries after ischaemic exercise has shown that it remains very low ( $<10 \%$ of the total leg resistance) $[4,5]$.
It seemed to us, therefore, that the findings could be equally well explained by changes in microvascular (as opposed to large vessel) distensibility. Therefore, we tested the hypothesis that the increase in blood flow produced by tilting was reduced in patients with microvascular disease. If the reduced response of maximum blood flow to head-up tilting was due to reduced distensibility of the microvascular bed, it should be expected that similar results would follow local relaxation of the vascular smooth muscle cells in the labelled area by the injection of papaverine [6], a procedure which does not measurably affect blood flow in larger arteries. Thus, the purpose of the present study was to evaluate the effect of head-up tilt on blood flow in the anterior tibial muscle as measured by the local isotope washout technique. Complete relaxation of the vascular bed was obtained either by local injection of papaverine or by maximal ischaemic exercise.

\section{Subjects and Methods}

Normal subjects $(n=5)$ who were free of symptomatic arterial disease and who had normal ankle pressures and pulses were studied. The median age was 37 years (range 32.40 years). The diabetic subjects $(n=6)$ included five males and one female and their median age was 35 years (25-38 years). All had normal ankle pressures and pulses 
Table 1. Blood pressure, and blood flow supine and after tilting in diabetic and non-diabetic subjects

\begin{tabular}{lll}
\hline & $\begin{array}{l}\text { Non-diabetic } \\
\text { subjects } \\
(n=5)\end{array}$ & $\begin{array}{l}\text { Diabetic } \\
\text { patients } \\
(n=6)\end{array}$ \\
\hline $\begin{array}{l}\text { Systemic blood pressure (mmHg) } \\
\text { Systolic }\end{array}$ & $\begin{array}{r}130(125-135) \\
\text { Diastolic }\end{array}$ & $\begin{array}{c}139(130-150) \\
89(80-85)\end{array}$ \\
$\begin{array}{l}\text { Post-ischaemic blood flow } \\
\left(\mathrm{ml} \cdot 100 \mathrm{ml}^{-1} \text { min }^{-1}\right)\end{array}$ & $70(51-107)$ & $81(45-10)$ \\
$\begin{array}{l}\text { Relative change in blood flow } \\
\text { after tilting }\end{array}$ & & \\
$\begin{array}{l}\text { Ischaemic exercise } \\
\text { Papaverine depot }\end{array}$ & $1.45(1.26-1.75)$ & $1.04(0.82-1.25)$ \\
\hline
\end{tabular}

Results given as median with range in parentheses.

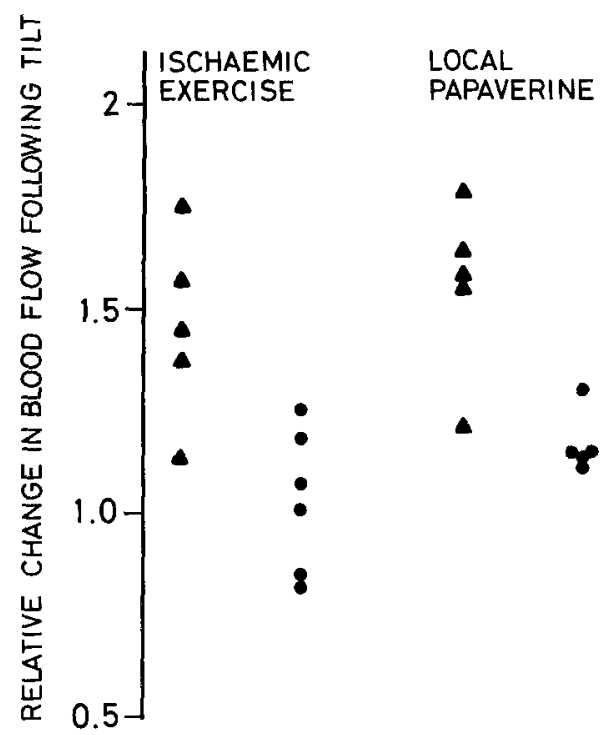

Fig. 1. Relative blood flow change after tilt expressed as the ratio of maximum clearance constants before and after $45^{\circ}$ head-up tilt. Left panel: after ischaemic exercise; right panel: after local papaverine. Normal subjects $\boldsymbol{\Lambda}$, diabetic patients

and there was no fall in ankle pressure following maximum ischaemic exercise. All had insulin-dependent diabetes, known median duration of 18 years (range 16-31 years). Renal function was assessed from the glomerular filtration rate and the amount of proteinuria. The median glomerular filtration rate was $87 \mathrm{ml} / \mathrm{min}$ per $1.73 \mathrm{~m}^{2}$ (range 54-101) and the amount of protein excreted was a median $2.2 \mathrm{~g} / 24 \mathrm{~h}$ (range 1.4-6.5). Two subjects had proliferative retinopathy, all the remainder had background retinopathy. None had significant postural hypotension. The change in systolic and diastolic blood pressure on standing was respectively $-6 \mathrm{mmHg}$ (range -12 to +4 ) and $4 \mathrm{mmHg}$ (range -6 to +10 ). The median heart rate increase was 18 beats/min (range 12-28). Six subjects who had severe atherosclerosis affecting a lower limb were also studied. Gangrene or rest pain was present in five of them. The median age was 66 years (range $52-76$ years). The severity of the ischaemia can be judged from the ankle and toe pressures measured by the strain-gauge technique [7]), which were $53 \mathrm{mmHg}$ (range 15-95) and $15 \mathrm{mmHg}$ (range 0-70), respectively. All subjects gave informed consent after the purpose and extent of the experimental procedure were explained.

Muscle blood flow was measured in the anterior tibial muscle using the radioisotope washout technique [8]. Two isotopes were used: iodine-antipyrine (IAP) labelled with ${ }^{131}$ I was used to measure the absolute blood flow following ischaemic exercise. For the study of changes in blood flow produced by tilting, the clearance of ${ }^{133} \mathrm{Xe}$ was measured. This procedure was adopted to minimize the dose of radiation from ${ }^{131} \mathrm{I}$ to which the subjects were exposed. The injection of $0.1-0.2 \mathrm{ml}$ of solution with $30-40 \mu \mathrm{Ci}^{131} \mathrm{IAP}$ was given slowly into the tibialis anterior muscle via a $4 \mathrm{~cm}$ long, $0.4 \mathrm{~mm}$ diameter needle. The ${ }^{131}$ IAP was obtained from EIGD Institut für Reaktorforschung Isotopenproduktion, Würenlingen, Switzerland. The solution contained $10 \mathrm{mmol}$ phosphate buffer ( $\mathrm{pH} \mathrm{7.0)}$, and the free iodine content was $<1 \%$. The injection of Xenon contained approximately $1 \mathrm{mCi}^{133} \mathrm{Xe}$ in $0.1-0.2 \mathrm{ml} 0.9 \% \mathrm{NaCl}$ (Radiochemical Centre, Amersham, UK).

The $\gamma$-emission was recorded by a scintillation detector with a $\mathrm{NaI}$ crystal $30 \mathrm{~mm}$ diameter, $25 \mathrm{~mm}$ thick, and the impulses recorded on a spectrometer (Meditronic, Copenhagen, Denmark). The detector was placed about $15 \mathrm{~cm}$ from the limb which was immobilized using a vacuum fixation pillow. The fractional clearance of isotope $(\mathrm{k} / \mathrm{min})$ was calculated from the slope of a semilogarithmic plot of the count rates (corrected for background activity), measured each $10 \mathrm{~s}$, versus time. During reactive hyperaemia, the activity was counted every $2 \mathrm{~s}$. The muscle blood flow (f) was calculated from

$\mathrm{f}=100 \cdot \lambda \cdot \mathrm{k} \mathrm{ml} \cdot 100 \mathrm{~g}^{-1} \cdot \min ^{-1}(9)$

where the tissue-blood partition coefficient $(\lambda)$ for antipyrine was taken as $1.0 \mathrm{ml} / \mathrm{g}$ and for ${ }^{133} \mathrm{Xe} 0.7 \mathrm{ml} / \mathrm{g}$.

\section{Experimental Procedure}

Effect of tiling: The effect of tilting head-up is to increase the vascular transmural pressure while maintaining the perfusion pressure constant, because tilting increases both arterial and venous pressures by the same amount. The increase in blood flow produced by an increased transmural pressure can be regarded as reflecting the distensibility of the vascular bed.

Local Papaverine Depot: Papaverine $0.4 \mathrm{ml}(30 \mathrm{mg} / \mathrm{ml})$ was mixed with the Xenon solution before injection. One minute after the injection, counting of Xenon activity was started and continued until a suitable tracing was obtained $(1-2 \mathrm{~min})$. The subject was then tilted $45^{\circ}$ head-up, the detector repositioned and another set of readings obtained.

Ischaemic Exercise: In the opposite leg, after a radioisotope depot had been injected, a tourniquet was inflated to $200 \mathrm{mmHg}$ just above the knee. The subject then performed active ankle movements until stopped by weakness or pain $(1.5-3.0 \mathrm{~min})$. Counting was begun, the cuff deflated and the counting continued for $1 \mathrm{~min}$. Ankle systolic pressure was measured. The table was tilted $45^{\circ}$, the tourniquet inflated and the exercise repeated $(0.75-1.25 \mathrm{~min})$. The disappearance of the radioactivity following deflation of the cuff was again studied. The atherosclerotic subjects were not studied after ischaemic exercise.

Statistical Methods: Results are given as the median for each value and differences between groups were tested by the Wilcoxon rank sum test.

\section{Results}

\section{Maximum Blood Flow}

The maximum blood flow following ischaemic exercise was similar in both diabetic and non-diabetic subjects. The maximum flow estimated from the clearance of antipyrine was $70 \mathrm{ml} \cdot 100 \mathrm{~g}^{-1} \cdot \mathrm{min}^{-1}$ (range 51-107) and in diabetic patients $81 \mathrm{ml} \cdot 100 \mathrm{~g} \cdot{ }^{-1} \cdot \mathrm{min}^{-1}$ (range 45-103). The systemic blood pressure was similar in the diabetic and non-diabetic subjects (Table 1). 


\section{Effect of Tilt on Blood Flow}

This has been expressed as the relative change in blood flow calculated as the ratio of the maximal washout rate constant (k) obtained when the subject was tilted to that when horizontal. Tilting produced an increase in hydrostatic pressure head of about $40 \mathrm{mmHg}$. After ischaemic exercise (Fig.1, left panel) the change in blood flow was greater in the normal than in the diabetic subjects $(T=17, p<0.05)$. In the local papaverine depot (Fig. 1, right panel), the change in blood flow was also greater in normal than in diabetic subjects $(T=16, p$ $<0.05$ ). (One diabetic subject, in whom there was a failure to paralyse the vascular smooth muscle as evidenced by a very low blood flow has been excluded from this analysis. This probably resulted from the injection being misplaced into adipose tissue).

The relative change in flow following tilting was similar in the two systems in each group (Table 1). In the normal subjects, the change after ischaemic exercise was $1.45(1.26-1.75)$ and in the locally relaxed bed 1.58 (1.21-1.78). In the diabetic patients, the respective values were $1.04(0.82-1.25)$ and $1.14(1.11-1.30)$. In the atherosclerotic patients, the relative increase in blood flow following tilting was $1.77(1.17-3.86)$. This was higher than in the diabetic subjects $(T=21, p<0.01)$.

\section{Discussion}

The main result of this study was that the increase in blood flow, induced by tilting in the totally relaxed vascular bed, was equally reduced in diabetic subjects by regional or local vasodilatation. Since locally injected papaverine did not alter the large artery pressure, the results strongly suggest that the reduced response in the diabetic subjects to tilting was due to a reduced distensibility of the microvascular bed. In this context, distensibility has been defined in terms of the decrease in resistance resulting from an increase in vascular transmural pressure while perfusion pressure remained constant.

Following ischaemic exercise and in the locally relaxed depots, maximum blood flow was similar in diabetic and non-diabetic subjects. Since perfusion pressure, estimated as the mean arterial pressure was similar, the resistance to blood flow must also have been the same. This finding is in agreement with previous reports $[3,10,11]$. Thus, we were unable to distinguish the responses of diabetic from normal subjects without the added stress of an increased transmural pressure. There was no difference in vascular resistance in the locally dilated vascular bed between normal and atherosclerotic subjects, suggesting that the distensibility of the microvascular bed was not reduced in atherosclerotic subjects, although the supine transmural pressure was low and tilting might cause a greater increase in flow.

The reduced distensibility of the microvessels in the diabetic patients might be due to structural changes which can be seen in histological studies [12]. Another explanation could be that the local vessels were unable to distend further because the elastic elements of the vessel wall were fully stretched [13]. If this latter explanation is correct, it should only be possible to increase blood flow by increasing perfusion pressure. However, several studies have indicated that increasing transmural pressure by postural changes or the application of negative pressure to the limb will cause an increase in blood flow, although perfusion pressure can be assumed to be unchanged $[6,11,14-16]$. The common finding has been that, when the transmural pressure was increased by about $40-50 \mathrm{mmHg}$, blood flow increased by about $50 \%$. The results from our normal subjects agree with this conclusion and the smaller response in the diabetic patients is consistent with a greater rigidity of the small vessels. Since the major part of the total vascular resistance is located in the small arterioles, even in the fully dilated vascular bed, these observations probably reflect decreased arteriolar distensibility.

The blood flow measured in the papaverine-relaxed depot was less than that seen after ischaemic exercise. The reason for this is uncertain, but may be because small and medium-size muscular arteries are dilated following ischaemic exercise but are unaffected in the small volume exposed to the papaverine. Despite this reservation, there is little doubt that the local bed behaved passively and the proportional changes in blood flow were similar to those following ischaemic exercise. In addition, loss of autoregulation in such a bed can be demonstrated when the depot area is elevated above heart level and this strongly suggests that near maximal dilatation has been produced.

We consider that the responses of the locally relaxed vascular bed provide a suitable model for studying microvascular resistance and may be preferable to ischaemic exercise because the reproducibility of the exercise response is critically dependent of the effort the subject applies to the performance of the exercice and requires a highly motivated subject.

Acknowledgement. I.F. was receiving a Danish Government Scholarship.

\section{References}

1. Folkow, B, Grimby G, Thulesius O (1958) Adaptive structural changes of the vascular walls in hypertension and their relation to the control of the peripheral resistance. Acta Physiol Scand 44: 255-272

2. Conway J (1963) A vascular abnormality in hypertension: a study of blood flow in the forearm. Circulation 27: 520-529

3. Neubauer B (1978) Tilted and non-tilted post-ischaemic exercise peak blood flow in the legs of long-term diabetic and normal subjects. Diabetologia 15: 9-11

4. Ludbrook $J$ (1966) Collateral artery resistance in the human lower limb. J Surg Res 6: 423-434

5. Sumner DS, Strandness DE (1970) The effect of exercise on resistance to blood flow in limbs with an occluded femoral artery. Vasc Surg 4:229-237 
6. Henriksen O, Kristensen J (1979) Distensibility of the papaverinerelaxed vascular bed in human subcutaneous tissue. Acta Physiol Scand 106: 109-113

7. Nielsen PE, Bell G, Lassen NA (1973) Strain gauge studies of distal blood pressure in normal subjects and in patients with peripheral arterial disease. Scand $\mathbf{J}$ Clin Lab Invest [Suppl] 31: 103-109

8. Lassen NA, Lindbjerg IF, Munck O (1964) Measurement of blood flow through skeletal muscle by intramuscular injection of Xenon-133. Lancet I: 686-689

9. Kety SS (1951) The theory and applications of the exchange of inert gas at the lungs and tissues. Pharmacol Rev 3:1-41

10. Munck O, Lindbjerg IF, Binder C, Lassen NA, Trap-Jensen $\mathbf{J}$ (1966) Skeletal muscle blood flow in diabetic patients determined by intramuscular injection of Xenon ${ }^{133}$. Diabetes 15: 323-326

11. Neubauer B (1977) Tilted and non-tilted post-ischaemic exercise peak flow in the legs of normal human subjects. Scand J Clin Lab Invest 37: 59-62

12. Goldenberg S, Alex M, Joshi RA, Blumenthal HT (1959) Nonatheromatous peripheral vascular disease of the lower extremities in diabetes mellitus. Diabetes 8: 261-273
13. Folkow B, Löfving B (1956) The distensibility of the systemic resistance vessels. Acta Physiol Scand 38: 37-52

14. Hartling O, Noer I, Trap-Jensen J (1976) Leg muscle blood flow during reactive hyperaemia. Pfluegers Arch 366: 131-135

15. Hartling O, Svendsen TL, Nielsen PE, Trap-Jensen J (1978) The distensibility of the resistance vessels of skeletal muscle in hypertensive patients. Acta Physiol Scand 103: 430-436

16. Henrikson O, Skagen K, Amtorp O, Hartling O (1981) Augmented vasoconstrictor response to changes in vascular transmural pressure in patients with essential arterial hypertension. Acta Physiol Scand 112: 323-329

Received: 2 December 1981

and in revised form: 1 July 1982

Dr. I. Faris

Department of Surgery

Royal Adelaide Hospital

Adelaide SA 5000

Australia 